\title{
Adolescent immunisation: the next big thing?
}

\author{
Adam Finn, ${ }^{1}$ Ed Clarke, ${ }^{1}$ Julie Mytton²
}

\section{INTRODUCTION}

The recent introduction of the human papillomavirus (HPV) vaccine into the routine immunisation schedule for girls in the UK has reaffirmed the possibility of widespread adolescent immunisation, assuming appropriate prior consultation and resource allocation. On the back of this success, it is timely to consider the case for extending the programme of school-based adolescent immunisations to include the provision of both additional primary immunisations as well as important booster doses of vaccines given earlier in childhood. Such a programme, if well designed, would ensure that individual protection from vaccine preventable disease was maximised prior to school leaving and, of equal importance in some cases, that herd immunity was sustained more effectively in the population as a whole. The possible contents of a re-invigorated adolescent immunisation programme are discussed considering those vaccines which are already available and for which cost-benefit calculation may therefore be of prime importance, as well as vaccines which may become available in the future and for which the issues may be more complicated. The importance of providing balanced, accurate, appropriate and accessible information regarding adolescent immunisation is also highlighted.

\section{INTRODUCTION OF THE HPV VACCINATION PROGRAMME}

The introduction of routine human papillomavirus (HPV) vaccination for 12-year-old girls in 2008 represented a return to a public health strategy which had been abandoned in the UK with the discontinuation of routine BCG: namely the use of a rolling school-based adolescent immunisation programme.

${ }^{1}$ Institute of Child Life and Health, University Hospitals Bristol Education Centre, University of Bristol, Bristol, UK; ${ }^{2}$ Department of Public Health, NHS Bristol, Bristol, UK

Correspondence to Professor Adam Finn, Institute of Child Life and Health, Level 6, University Hospitals Bristol Education Centre, University of Bristol, Upper Maudlin Street, Bristol BS2 8AE, UK; adam.finn@ bristol.ac.uk
Although not without problems, ${ }^{1}$ the programme has been very successful to date, with uptake rates of between $80 \%$ and $90 \% .^{2}$ Furthermore, despite concerns to the contrary, a workable and effective means of involving both parents and children in the consent process has been implemented. ${ }^{3-5}$ Inevitably, disorders developing during the days, weeks and months after immunisation will continue to be attributed to the vaccine by some, despite the availability of valuable baseline epidemiology against which incidence rates can be benchmarked. ${ }^{67}$ But, with luck, both the public and the media will have learnt enough following the false alarmism surrounding measles mumps rubella (MMR) and autism, to know that chronology does not always denote causality. On the back of this success, is there scope to widen this approach to include other vaccines for which a case can be made for universal administration, to young teenagers and, in association with this, is there a case for offering HPV immunisation to boys as well as girls?

It is not hard to find additional candidates. A booster vaccine combining tetanus, low dose diphtheria and trivalent inactivated polio (Td/IPV) is already recommended for teenagers aged between 13 and 18 years of age within the standard schedule. However, reported uptake rates of $\mathrm{Td} / \mathrm{IPV}$ are highly variable between primary care trusts (PCTs) due to differences in the Child Health reporting systems. Some areas are unable to report any data, while others under-report due to incomplete age groups or incomplete identification of children eligible to receive the booster. ${ }^{8}$ Transferring this programme to run alongside HPV for girls, and as a platform upon which to build a secondary school-based programme for boys would require standardisation of collection systems for the Td/IPV booster and should lead to complete and accurate recording of uptake rates. Ensuring that more individuals receive a fifth dose of these antigens is important as they are thought to be required to ensure reliable individual protection into adult life. A small further step would see the addition of acellular pertussis to the Td/IPV adolescent vaccine. Indeed, adolescent pertussis vaccination has already been instituted in a number of countries including France, Germany and the USA following its recommendation by the Global Pertussis Initiative. ${ }^{9} 10$ Currently, severe and fatal cases of pertussis continue to occur in infants too young to have been fully immunised. Epidemiological studies suggest that this is because Bordetella pertussis continues to circulate, particularly in young adults whose vaccine-induced immunity has worn off, causing persistent coughs and, on rare but devastating occasions, transmission to their recently born offspring or other infant contacts. ${ }^{11}$

Notwithstanding the eventual triumph, in the UK in 1988, of universal rubella immunisation over selective immunisation of young adolescent girls, cost-benefit calculations have effectively ruled out offering HPV vaccine to adolescent boys, at least for the present ${ }^{12}$ and have also resulted in UK use of bivalent rather than quadrivalent HPV vaccine. However, such considerations might not apply to immunisation against the other vaccine-preventable, sexually transmitted, cancer-causing virus-hepatitis B, as the vaccine is much cheaper. In 1992, the WHO recommended universal hepatitis $B$ immunisation in all countries, giving the option of adolescent, rather than infant immunisation in low prevalence countries, such as the UK. ${ }^{13}$ Discussions about the implementation of universal hepatitis B immunisation in the UK are on-going and could eventually culminate in inclusion of the vaccine into the infant schedule if the logistics and cost can be got right. An alternative for the UK could be the immunisation of young teenagers, close to the age of onset of sexual activity. The communication issues are similar to those relating to HPV-in the end the only major difference from the recipient's perspective is that the cancer to be prevented is in a different organ. Furthermore, the three dose schedules match and it is already known that the vaccines can be given concomitantly without loss of the protective efficacy of either. ${ }^{14}$

Meningococcal disease in the UK primarily affects infants and young children, with a second smaller peak occurring in adolescents. ${ }^{15}$ The overall incidence rates and relative predominance of different meningococcal serogroups varies widely between continents and regions and this has influenced how vaccines have been 
developed and used. Effective conjugated capsular polysaccharide vaccines are now licensed and available in Europe against disease caused by serogroups A, C, Y and $W_{135}$. In contrast, vaccines against serogroup B strains (Men B) have been much harder to develop although they have been used to control epidemic disease, caused by single strains in Cuba and New Zealand. ${ }^{16-18}$ Furthermore, at least one vaccine with predicted efficacy against a proportion of endemic Men B disease is in clinical trials in the UK. ${ }^{17} 19$ Disease caused by Men C, a serogroup previously prevalent in the UK, has dramatically reduced following introduction of universal Men $C$ conjugate vaccination in 1999-2000. ${ }^{20}$ However, the introduction included a large catch-up programme in children and young adults then aged up to 23 years. The greater population coverage, with associated herd immunity, afforded by the catch-up programme is progressively disappearing as the immunised cohort gets older and is replaced by children who have only been immunised in infancy or, since 2006, infancy and the second year of life. Recent evidence indicates that antibody levels in children such as this, immunised in early life, fall away towards baseline by the age of between 2 and 3 years. ${ }^{21}$ Accordingly we may be heading towards a situation where Men C disease starts to return, ${ }^{22}$ somewhat like the re-emergence of $\mathrm{Hib}$ disease early in the first decade of this century. $^{23}$ The logical solution is probably, once again, adolescent booster immunisation-an approach given further impetus by the fact that currently available evidence suggests that immune responses may be significantly longer-lasting if the vaccines are given in the second decade of life than if they are given early in the first. ${ }^{24}$ Adolescent booster immunisation could therefore serve, not only to generate long lasting protection for the individual, but also to sustain herd immunity in the population as a whole. Such boosting could be with conjugate Men $C$ vaccine or, given that small numbers of cases of Men A, Y and $\mathrm{W}_{135}$ disease do occur, with quadrivalent vaccine instead, assuming the cost-benefit calculations could be made to work. ${ }^{25}$ 26 Similar arguments may apply to Men $B$ vaccines if and when vaccines with the necessary breadth of coverage in the UK become available and if they are shown to reduce incidence of carriage.

Media interest in the fact that immunisation against varicella is not routine in the UK was rekindled recently. Such awakenings are normally driven by a severe or fatal case of chickenpox, but on this occasion the trigger was a positive opinion from the Joint Committee on Vaccination and Immunisation concerning zoster vaccine for older people. ${ }^{27}$ Alongside cost-benefit calculations, a hypothetical temporary increase in zoster rates consequent upon disappearance of varicella cases among children and thus, in principle, a reduction in the boosting of cell mediated immunity in their adult contacts, is frequently cited as a bar to universal childhood immunisation. ${ }^{28} 29$ In reality, reluctance to destabilise the recovery of the thoroughly disrupted MMR programme by adding varicella either alongside it or combined as MMRV may be at least as important. While such deliberations play themselves out, an opportunity exists, within a reinvigorated adolescent programme, to immunise adolescents with no history of chickenpox, as has been advocated in the USA. ${ }^{30}$ Adults who get varicella are more likely to get seriously ill than children, so that protecting the one in 20 or so who escape the infection in childhood makes good sense. The rash is easily recognised so a positive history is fairly specific. ${ }^{31}$ While many individuals with a negative history will nonetheless be immune, ${ }^{31}$ unnecessary vaccination will do no harm and could be done easily within an established school based immunisation programme for all teenagers whereas the cost and logistics of doing serological screening prior to vaccination make this unlikely to be workable.

What other developments could occur in adolescent immunisation in the foreseeable future? A broader range of vaccines against sexually transmitted infections (STIs) may become available. As occurred with HPV vaccine, there will be some who argue against progressing in this direction on moral grounds, proposing that it will remove an inhibition to initiation of sexual behaviour. Whether or not the prevailing consensus endorses such views, vaccines against STIs including herpes simplex virus type 2 and chlamydia are likely to become available in the future ${ }^{32-34}$ and this will raise questions about whether and how to deploy them.

More generally, PCTs might choose to use the well-established and robust Child Health systems containing the immunisation status of preschool children resident in their patch, to permit clinical staff running school programmes to ascertain precise details of each child's previous immunisations so that missed vaccine doses can be given at school-based sessions, maximising individual and herd protection. This could reduce the recent regular outbreaks of mumps in university students, some of which have been widespread. ${ }^{35}$ Such a facility could mean that, over time, the requirement for occasional catch-up programmes, as required in recent times with measles, ${ }^{36}$ which are both expensive and logistically difficult to organise over and above more regular workloads, could be avoided. School Nursing Teams have been stretched to deliver the current HPV catch up programme as well as their pre-existing commitments, so the establishment of a routine school based adolescent immunisation programme would require careful workforce planning. The ability to expand workforces would be challenging in the current financial climate. Finally the existence of a well-established school programme would provide an infrastructure upon which occasional unscheduled requirements, such as the delivery of pandemic flu vaccines, could much more easily be added.

The provision of immunisation to teenagers needs to be done with some consideration. Reports of epidemics of needle-phobia-related fainting among girls queuing for HPV vaccine provide examples of suboptimal organisation. ${ }^{6}$ Conversely some of the information developed to provide information about the vaccine to this target group in the UK appears to have been well designed and well received. The future success of immunisation at all ages depends critically upon the effective provision of accurate, balanced, understandable, and when asked for, detailed information both about particular vaccines and about immunisation in general instead of the standard diet of scare stories. Nowhere will this be more pertinent than among adolescents.

Competing interests AF undertakes clinical research sponsored by and paid consultancy for and has received speaking honoraria and costs related to attending academic meetings from all the major vaccine manufacturers. All income is paid into his employers, the University of Bristol and University Teaching Hospitals Bristol NHS Foundation Trusts. EC has been funded to attend academic meetings by a number of major vaccine manufacturers.

Provenance and peer review Commissioned; internally peer reviewed.

Accepted 12 May 2010

Published Online First 6 July 2010

Arch Dis Child 2011;96:497-9.

doi:10.1136/adc.2010.192070 


\section{REFERENCES}

1. O'Dowd A. Teenager who died after having HPV vaccine had a malignant chest tumour. BMJ 2009;339:b4032.

2. Department of Health. Annual HPV Vaccine Uptake Rate in England: 2008/2009. 2010.

3. Brabin L, Roberts SA, Stretch R, et al. Uptake of first two doses of human papillomavirus vaccine by adolescent schoolgirls in Manchester: prospective cohort study. BMJ 2008;336:1056-8.

4. Brabin L, Roberts SA, Stretch R, et al. A survey of adolescent experiences of human papillomavirus vaccination in the Manchester study. Br J Cancer 2009;101:1502-4.

5. Brown EC. Human papillomavirus vaccine: Some issues around consent remain unresolved. BMJ 2008;336:1146.

6. Tanne JH. Questions over human papillomavirus vaccine in the US and Australia. BMJ 2007;334:1182-3.

7. Siegrist CA, Lewis EM, Eskola J, et al. Human papilloma virus immunization in adolescent and young adults: a cohort study to illustrate what events might be mistaken for adverse reactions. Pediatr Infect Dis J 2007;26:979-84.

8. The NHS Information Centre. NHS Immunisation Statistics 2008-2009 Version 1.0. 2009.

9. Forsyth KD, Wirsing von Konig $\mathrm{CH}$, Tan $\mathrm{T}$, et al. Prevention of pertussis: recommendations derived from the second Global Pertussis Initiative roundtable meeting. Vaccine 2007;25:2634-42.

10. Forsyth KD, Campins-Marti M, Caro J, et al. New pertussis vaccination strategies beyond infancy: recommendations by the global pertussis initiative. Clin Infect Dis 2004;39:1802-9.

11. Schellekens J, von König CH, Gardner P. Pertussis sources of infection and routes of transmission in the vaccination era. Pediatr Infect Dis J 2005;24:S19-24.

12. Marra F, Cloutier K, Oteng B, et al. Effectiveness and cost effectiveness of human papillomavirus vaccine: a systematic review. Pharmacoeconomics 2009;27:127-47.

13. Expanded programme on immunization. Global Advisory Group - part I. Wkly Epidemiol Rec 1992;67:11-15.

14. Finney M, Vaughan T, Taylor S, et al. Characterization of the key antigenic components and pre-clinical immune responses to a meningococcal disease vaccine based on Neisseria lactamica outer membrane vesicles. Hum Vaccin 2008:4:23-30.

15. Trotter CL, Gay NJ, Edmunds WJ. The natural history of meningococcal carriage and disease. Epidemiol Infect 2006;134:556-66.

16. Sierra GV, Campa HC, Varcacel NM, et al. Vaccine against group B Neisseria meningitidis: protection trial and mass vaccination results in Cuba. NIPH Ann 1991;14:195-207; discussion 208-10.

17. Vaughan AT, Gorringe A, Davenport $\mathrm{V}$, et al. Absence of mucosal immunity in the human upper respiratory tract to the commensal bacteria Neisseria lactamica but not pathogenic Neisseria meningitidis during the peak age of nasopharyngeal carriage. J Immunol 2009;182:2231-40.

18. Lennon D, Jackson C, Wong S, et al. Fast tracking the vaccine licensure process to control an epidemic of serogroup B meningococcal disease in New Zealand. Clin Infect Dis 2009;49:597-605.

19. Lucidarme J, Comanducci M, Findlow J, et al. Characterisation of $\mathrm{fHbp}$, nhba (gna2132), nadA, porA and Sequence Type in group B meningococcal case isolates collected in England and Wales during January 2008, and potential coverage of an investigational group B meningococcal vaccine. Clin Vaccine Immunol 2010; (In Press).

20. Campbell H, Borrow R, Salisbury D, et al. Meningococcal $C$ conjugate vaccine: the experience in England and Wales. Vaccine 2009;27(Suppl 2):B20-9

21. Borrow R, Andrews N, Findlow H, et al. Kinetics of antibody persistence following administration of a combination meningococcal serogroup $\mathrm{C}$ and Haemophilus influenzae type b conjugate vaccine in healthy infants in the United Kingdom primed with a monovalent meningococcal serogroup $C$ vaccine. Clin Vaccine Immunol 2010;17:154-9.

22. Pollard AJ, Perrett KP, Beverley PC. Maintaining protection against invasive bacteria with proteinpolysaccharide conjugate vaccines. Nat Rev Immunol 2009;9:213-20.

23. Rijkers GT, Vermeer-de Bondt PE, Spanjaard L, et al. Return of Haemophilus influenzae type b infections. Lancet 2003;361:1563-4.

24. Snape MD, Kelly DF, Lewis S, et al. Seroprotection against serogroup $\mathrm{C}$ meningococcal disease in adolescents in the United Kingdom: observational study. BMJ 2008;336:1487-91.
25. Gasparini R, Conversano M, Bona G, et al. Randomized trial on the safety, tolerability, and immunogenicity of MenACWY-CRM, an investigational quadrivalent meningococcal glycoconjugate vaccine, administered concomitantly with a combined tetanus, reduced diphtheria, and acellular pertussis vaccine in adolescents and young adults. Clin Vaccine Immunol 2010;17:537-44.

26. Ostergaard L, Lebacq E, Poolman J, et al. Immunogenicity, reactogenicity and persistence of meningococcal A, C, W-135 and Y-tetanus toxoid candidate conjugate (MenACWY-TT) vaccine formulations in adolescents aged $15-25$ years. Vaccine 2009;27:161-8.

27. Joint Committee on Vaccination and Immunisation. Statement of Varicella and Herpes Zoster Vaccines. 2010.

28. Thomas SL, Wheeler JG, Hall AJ. Contacts with varicella or with children and protection against herpes zoster in adults: a case-control study. Lancet 2002;360:678-82.

29. Brisson M, Gay NJ, Edmunds WJ, et al. Exposure to varicella boosts immunity to herpes-zoster: implications for mass vaccination against chickenpox. Vaccine 2002;20:2500-7.

30. Boyaka PN, Wright PF, Marinaro M, et al. Human nasopharyngeal-associated lymphoreticular tissues. Functional analysis of subepithelial and intraepithelial B and T cells from adenoids and tonsils. Am J Pathol 2000;157:2023-35.

31. Holmes CN. Predictive value of a history of varicella infection. Can Fam Physician 2005;51:60-5.

32. Christiansen G, Birkelund S. Is a Chlamydia vaccine a reality? Best Pract Res Clin Obstet Gynaecol 2002;16:889-900.

33. Rupp R, Bernstein DI. The potential impact of a prophylactic herpes simplex vaccine. Expert Opin Emerg Drugs 2008;13:41-52.

34. Stanberry LR, Spruance SL, Cunningham $A L$, et al. Glycoprotein-D-adjuvant vaccine to prevent genital herpes. N Eng/ J Med 2002;347:1652-61.

35. Health Protection Agency. Laboratory confirmed cases of measles, mumps and rubella, England and Wales: April to June 2005. CDR Weekly Report 2005:15:16-18.

36. Chief Medical Officer. PL CMO (2008)5: The MMR Vaccination Catch-Up Programme. 2008. 


\section{Adolescent immunisation: the next big} thing?

Adam Finn, Ed Clarke and Julie Mytton

Arch Dis Child 2011 96: 497-499 originally published online July 6, 2010 doi: 10.1136/adc.2010.192070

Updated information and services can be found at:

http://adc.bmj.com/content/96/6/497.full.html

\section{These include:}

References This article cites 31 articles, 11 of which can be accessed free at: http://adc.bmj.com/content/96/6/497.full.html\#ref-list-1

Email alerting Receive free email alerts when new articles cite this article. Sign up in service the box at the top right corner of the online article.

Notes

To request permissions go to:

http://group.bmj.com/group/rights-licensing/permissions

To order reprints go to:

http://journals.bmj.com/cgi/reprintform

To subscribe to BMJ go to:

http://group.bmj.com/subscribe/ 